\title{
The Frequency of Birds over the High Atlantic Ocean.
}

\author{
By P. Jespersen, Copenhagen.
}

THE Danish Commission for the Study of the Sea has, during the years I9I 3 and $1920-1922$, under the direction of Dr. Johs. Schmidt, made a series of marine-biological investigations in the northern part of the Atlantic Ocean and in West Indian waters. The following four expeditions have been carried out: in I9I3 with the schooner Margrethe, in 1920 and I92I with the motor-schooner Dana, and in I92 I-I922 with the research steamer Dana. So far as circumstances permitted, ornithological observations were also made on these expeditions, and it is on the diary of these observations, in combination with notes made on various voyages to the United States of America and to the West Indies, that the present account is based. In this I shall endeavour to give, on general lines, an idea of the frequency of birds over the various parts of the Atlantic.

In what follows I deal only with observations made on the ocean, and as such I consider those made at places where the distance from land was at least $5^{\circ}$ miles. We have in all, observations on the high seas on 462 days, covering an area from the Faroes (about $62^{\circ} \mathrm{N}$. lat.) to about $5^{\circ} \mathrm{N}$. lat. In the area between $10^{\circ}$ and $50^{\circ} \mathrm{N}$. lat. the observations cover the whole breadth of the Atlantic from the coasts of Europe and Africa right across to the coast of America, whereas north of $50^{\circ} \mathrm{N}$. lat. observations were available only for the eastern part of the Atlantic. Of the total number of days of observation the greater part, namely 254 days (about 55 per cent.), were spent in the area between $20^{\circ}$ and $40^{\circ} \mathrm{N}$. lat. and $40^{\circ}-70^{\circ} \mathrm{W}$. long., thus chiefly in the Sargasso Sea. Observations were made at all times of the year, the majority (about 62 per cent.), however, having been made in the six summer months, and there are few observations for the winter months north of $40^{\circ} \mathrm{N}$. lat.

It is well known that the frequency of birds differs greatly in the various parts of the Atlantic. In general, it may be said that the frequency decreases greatly with the distance from land, but there are also other circumstances which may have an influence in this respect.

In order to be able to form an opinion as to how far the frequency of birds varies for the different parts of the Atlantic, I have, on the basis of the daily observations mentioned, calculated the average number of birds observed per diem in the various areas. Of course these figures can by no means claim to be in any way accurate, in particular for areas where the number of birds is large, but they appear to be sufficient for giving an idea whether the frequency of birds is great or small in the various parts of the Atlantic. On the accompanying chart (Fig. I) the average number of birds observed per diem within an area of Io degrees longitude and to degrees latitude has been given. The figures in parenthesis give the number of days on which observa-

tions were made within the respective areas. As mentioned above, only observations have been included which were made on the high sea (at a distance from land of at least 50 miles), and only such birds have been considered which may be assumed as generally living over the high sea. Characteristic coast birds and all inland birds have been excluded from these calculations.

I have employed the following method in making my calculations : so far as possible, the number of all birds seen in the course of a day was noted down. In areas where birds appear in large flocks, the number could, of course, only be estimated, and the figures given for such areas, therefore, make no claim to great accuracy. I have in such instances placed a $>$ before

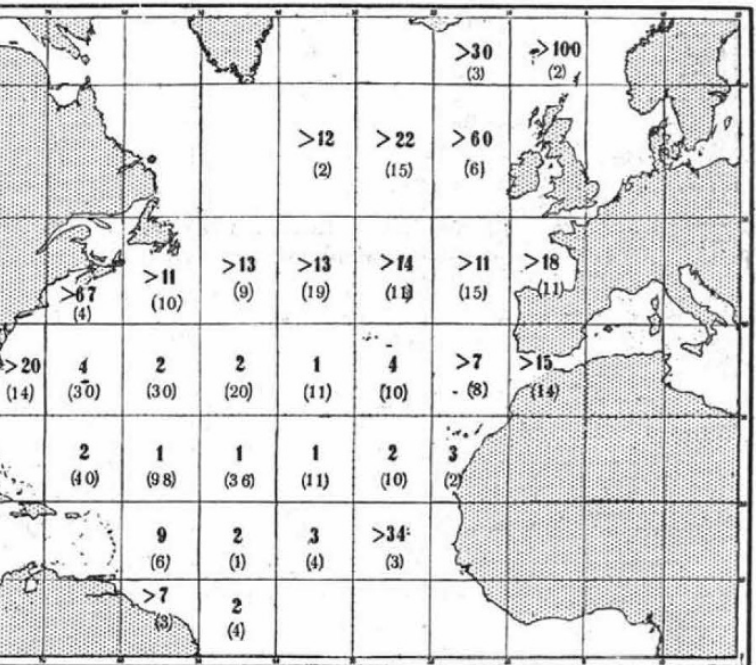

ge number of birds observed in $10^{\circ}$ areas. The figures in brackets give the numier of days on which observations were made in each area.

the number. When an average number is given for a certain area as, say, $>13$, this signifies that the average number of birds observed per diem within the respective area should be taken as, at the least, I 3 birds. In many instances the actual number will probably be considerably higher. Birds which had followed the ship steadily for the whole day were counted once only, and the maximum number of birds seen together at one time during the day is, in such cases, given as the number of birds observed that day. Of course, there is always the possibility that the same individual bird is counted several times a day, and I have tried to avoid this so far as possible, but, particularly where individual birds of the same species are concerned, there will always remain the possibility of a repeated observation of one and the same individual. When a bird has been observed several times a day about the ship, I have considered it to be the same if at least six hours had not elapsed between the individual observations. Naturally fractions have resulted in these calculations, but all such fractions have been neglected. The average figure may therefore be understood thus: the number I means that the average

No. 2860 , vol. I I 4 ] 
number of birds seen lies between $\mathrm{I}$ and 2 , the number 2 that the average number lies between 2 and 3 , and so on.

It is thus clearly seen in the accompanying chart that the frequency of birds is relatively larger the shorter the distance from land. Let us first consider the frequency of birds north of $40^{\circ} \mathrm{N}$. lat. Here we have the largest number in the neighbourhood of the Faroes and to the west of Ireland. In the Bay of Biscay the frequency of birds is, however, considerably lower. The birds predominating in quantity here were fulmars, shearwaters, skuas, and kittiwakes.

Along the coast of America we have a high average figure south of Nova Scotia $(>67)$. This is, in particular, caused by the large number of Wilson's petrels (Oceanites oceanicus Kuhl) which appears in the Gulf Stream area during the summer.

It will be observed that the frequency of birds decreases considerably with the distance from land north of $50^{\circ} \mathrm{N}$. lat., but that we have quite considerable

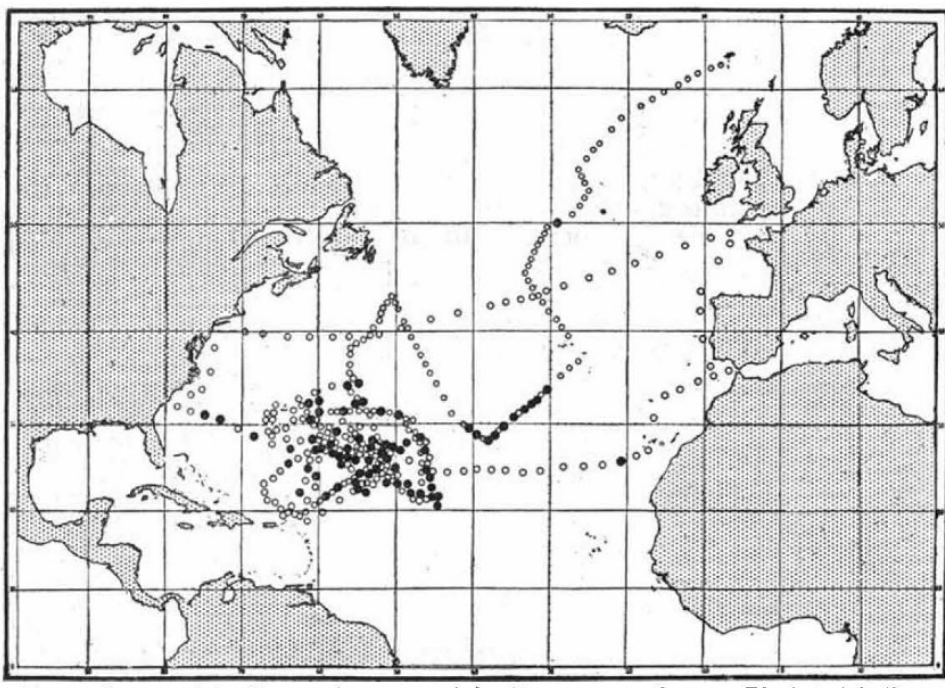

Fig, 2,-Routes of the Margrethe, 1913, and the Dana, rgzo and r92x. Black dots indicate positions in which no birds were observed during the day. numbers over the middle of the ocean. The same applies to the area between $40^{\circ}$ and $50^{\circ} \mathrm{N}$. lat. Across the whole breadth of the Atlantic Ocean we, everywhere, meet birds in large numbers. It appears that the average figure is nowhere less than II birds a day. We are here chiefly in the Gulf Stream area, and the birds predominant are shearwaters, kittiwakes, skuas, and petrels.

South of $40^{\circ} \mathrm{N}$. lat. we notice that the frequency of birds decreases greatly. We have, particularly, ample data on bird life between $20^{\circ}$ and $40^{\circ} \mathrm{N}$. lat., and it will be seen that the number of birds is particularly small within those parts of the northern Atlantic which is generally termed the Sargasso Sea. Regarding the area between $30^{\circ}$ and $70^{\circ} \mathrm{W}$. long., it will be observed that, with the exception of the Bermuda area, the number of birds, on the average, does not exceed I-2 per diem. The most characteristic bird for the Sargasso Sea is the tropic-bird (Phaëthon americanus Grant), but besides this bird we also observed in smaller numbers various petrels, shearwaters, and kittiwakes.

Between $30^{\circ}$ and $40^{\circ} \mathrm{N}$. lat. we have, however, a high frequency along the east coast of the United States and about Madeira, and in the Bay of Cadiz. Between $20^{\circ}$ and $30^{\circ} \mathrm{N}$. lat. the average numbers are particularly low across the whole ocean. South of $20^{\circ} \mathrm{N}$. lat. we find a surprisingly high average figure about the Cape Verde Islands, owing to the sooty-tern (Sterna fuscatio L.) appearing in flocks. The number of days on which observations were made here is, however, so small that no particular importance can be given to the individual figures.

The great difference between the number of birds on the high sea north and south of $40^{\circ} \mathrm{N}$. lat. is thus striking. For still further illustrating this difference we shall, in what follows, consider another circumstance. During the various voyages it happened, repeatedly that, on some days, not a single bird was seen from the ship, and it is of interest to have a look at the geographical position of such days of observation on which no birds whatever were seen. In the following chart (Fig. 2), showing the routes taken by the Margrethe in I9I 3 and by the Dana in I920 and r92x, the days of observation are marked. The black dots indicate the positions in which no birds were seen during the day.

It thus clearly appears that almost all days of observation on which no birds were seen were south of $40^{\circ} \mathrm{N}$. lat., being I day and 73 days respectively north and south of this latitude. The percentages are $\mathrm{I} \cdot 3$ and $28 \cdot \mathrm{x}$ respectively of all days of observation. This circumstance, furthermore, shows how small is the number of birds south of $40^{\circ} \mathrm{N}$. lat. compared with the parts of the Atlantic north of this latitude.

The longest period during which the Danish expeditions did not see any birds was four days, and the longest periods during which no birds were seen were all within the range of the Sargasso Sea, where the distance from land is considerable.

According to the available observations, it appears that the number of birds within the range of the Gulf Stream is at least ten times as large as in the Sargasso Sea, and the question arises: what is the reason that birds are so scarce in the Sargasso Sea as compared with the area of the Gulf Stream? In large portions of the Sargasso Sea the distance from the nearest land is very great, and it is therefore possible that this fact is one of the reasons for the scarcity of birds, but this can scarcely be the real reason. In the central parts of the Atlantic, between $40^{\circ}$ and $50^{\circ} \mathrm{N}$. lat., where the distance from land is very considerable, the frequency of birds is, relatively, much larger than in any part of the Sargasso Sea.

The reason for the scarcity of birds in the Sargasso Sea is far more probably to be found in the small amount of food in this part of the ocean as compared to the Gulf Stream area. It seems reasonable to assume that the special fauna (fishes, crabs, etc.) belonging to the large quantity of drifting "Gulfweed" (Sargassum) must afford nourishiment for more extensive bird life, but it is questionable whether this. fauna plays any part as food for birds in the Sargasso. Sea. 
I have thus, in examining the contents of the stomachs of birds from the Sargasso Sea, never found the slightest trace of the characteristic fauna from the Sargassum, and it is therefore possible that it is difficult for the birds to catch the fishes and crabs hiding in these dense masses of drifting sea-weed. Examinations of the stomachs have, on the other hand, always shown that the birds, at least the majority of them, live on flying fishes and cephalopods. This shows that the birds in the Sargasso Sea do not avail themselves of the special Sargassum fauna but seek their food amongst fishes, cephalopods, etc., living free in the water.

It is therefore interesting to study the quantity of macroplankton to be found in the Sargasso Sea and the Gulf Stream respectively. In a previous paper ${ }^{1}$ I have drawn a comparison between the quantity of macroplankton in various parts of the Atlantic, and it appears from this comparison that the quantity of macroplankton in the central parts of the Atlantic between $40^{\circ}$ and $50^{\circ} \mathrm{N}$. lat. is at least ten times as great as that in the Sargasso Sea.

The reason for the scarcity of bird life in the Sargasso Sea, as compared to that in the Gulf Stream area and, on the whole, in the northern Atlantic, may, therefore, safely be sought in the much smaller quantity of food to be found in the Sargasso Sea as compared to the parts of the Atlantic lying farther north.

1 P. Jespersen : On the Quantity of Macroplankton in the Mediterranean and the Atlantic. Rep. on the Danish Oceanogr. Expeditions, I908-10, vol. iii. 3. Copenhagen, 1923 .

\section{The Planet Mars.}

\section{By Dr. W. H. Steavenson.}

TH year's favourable opposition of Mars, which on August 22 is nearer to the earth than at any time between the eighteenth and twenty-first centuries, would seem a fitting occasion for a brief review of our present knowledge of the planet, together with an estimate of the prospects and probable direction of future research.

The object aimed at in physical observations of Mars may be considered as twofold. First, it is desired to determine, so far as available means will allow, the true appearance of the features presented to our view on the planet's surface ; and, secondly, it is hoped, by careful and repeated observation of these features and the changes that occur in them, to reach some definite conclusions as to their real nature. Both of these objects have been kept in view from the earliest days of the telescope, but it is only in recent years that the second of them has begun to show reasonable prospect of fulfilment. The fact is, of course, that the one object is dependent on the other, so that the first must be attained, approximately at least, before the second can be pursued with any confidence of success. Thus it comes about that the history of Martian observation naturally divides itself into two stages, which we may term respectively that of cartography and that of interpretation. One, of course, is but a development of the other, and there is no sharp dividing line between the two.

From the earliest days of the telescope, it was recognised that the "spots on Mars" were relatively permanent features of the planet's surface, but the first attempts to construct even a rough map of them did not meet with much success. The drawings made by Sir William Herschel late in the eighteenth century are among the first on which we can recognise a number of markings that have since become familiar to us, and it was this great astronomer who, by his study of the polar caps, contributed the first piece of intelligent interpretation of Martian phenomena. But the first map of Mars, properly so called, was not produced until I840, when Beer and Mädler gave to the world the results of their systematic work with a refractor of less than four inches aperture. This first map was followed, during the succeeding fifty years, by many others of increasing completeness and accuracy, each being in general the work of a single observer. During this period, thanks largely to the work of Schiaparelli, the areographical positions of the main features were fixed with some approach to finality, and a firm foundation was thus laid for future work. Finally, during the past thirty years or so, progress in cartography has been notably accelerated by the introduction of the co-operative system in observation, as exemplified by the work of such bodies as the British Astronomical Association. Meanwhile, as a result of these advances, we have begun to feel ourselves in a position to attack the problem of rational interpretation, based on the data so far accumulated. Much has, in fact, already been accomplished in this direction, and it is satisfactory to find that the theories are beginning to stand the crucial test of prediction.

To summarise all that is so far known with certainty is not altogether easy, for many of the results of observation, doubtless in most cases quite trustworthy, still lack that general confirmation which would justify us in accepting them with complete confidence. However, the following would probably be accepted on all hands as a fair statement of the present condition of definite knowledge concerning Mars.

(x) The fact of the general permanence of the larger dark markings has been established, and their positions and outlines have been determined with considerable accuracy. In other words, we are in a position to construct a very recognisable map of the planet, as regards its main features.

(2) As a result of the above, it has been possible to ascertain the inclination of the planet's axis within a few minutes of arc, and to determine the rotation period within less than a tenth of a second of time.

(3) The size and rate of diminution of the polar caps has been shown to bear a definite relation to $(a)$ the progress of the Martian seasons, $(b)$ the distance of the planet from the sun, and $(c)$ the extent of solar radiation as indicated by the sun-spot cycle. There is now general agreement that the caps must represent frozen water, the alternative of carbon dioxide, suggested some years ago, being for many reasons untenable.

(4) The large dark markings, while in general permanent in position and outline, are known to 